\title{
Drug-induced interstitial lung disease: mechanisms and best diagnostic approaches
}

\author{
Osamu Matsuno*
}

\begin{abstract}
Drug-induced interstitial lung disease (DILD) is not uncommon and has many clinical patterns, ranging from benign infiltrates to life-threatening acute respiratory distress syndrome. There are two mechanisms involved in DILD, which are probably interdependent: one is direct, dose-dependent toxicity and the other is immune-mediated. Cytotoxic lung injury may result from direct injury to pneumocytes or the alveolar capillary endothelium. Drugs can induce all types of immunological reactions described by Gell and Coombs; however, most reactions in immunemediated DILD may be T cell-mediated.

DILD can be difficult to diagnose; diagnosis is often possible by exclusion alone. Identifying the causative drug that induces an allergy or cytotoxicity is essential for preventing secondary reactions.

One method to confirm the diagnosis of a drug-induced disease is re-exposure or re-test of the drug. However, clinicians are reluctant to place patients at further risk of illness, particularly in cases with severe drug-induced diseases. Assessment of cell-mediated immunity has recently increased, because verifying the presence or absence of drug-sensitized lymphocytes can aid in confirmation of drug-induced disease. Using peripheral blood samples from drug-allergic patients, the drug-induced lymphocyte stimulation test (DLST) and the leukocyte migration test (LMT) can detect the presence of drug-sensitized T cells. However, these tests do not have a definite role in the diagnosis of DILD. This study explores the potential of these new tests and other similar tests in the diagnosis of DILD and provides a review of the relevant literature on this topic.
\end{abstract}

Keywords: DILD, Drug-induced interstitial lung disease, DPT, drug provocation test, DLST, Drug-induced lymphocyte stimulation test, LMT, leukocyte migration test

\section{Introduction}

Several types of drugs can cause drug-induced interstitial lung disease (DILD). The incidence of DILD for each individual drug is variable. DILD may be mild to progressive. In its more severe manifestation, DILD may result in respiratory failure and acute respiratory distress syndrome. DILD may develop within the first few days of treatment or may not until several years after treatment. DILD is generally described in terms of its clinical/ histopathological features. The mechanisms involved in drug-induced lung injuries are unclear; therefore, DILD cannot be classified in terms of pathogenesis.

Diagnosis of DILD generally depends on a definite temporal association between an exposure to the

\section{Correspondence: matsunoo@ra.opho.jp}

Division of Medicine for Allergic Disease, Osaka Prefectural Medical Center for Respiratory and Allergic Diseases, 3-7-1 Habikino, Habikino City, Osaka 583-8588, Japan causative agent and the development of respiratory signs and symptoms. The most important for accurate diagnosis is the exclusion of other causes of lung damage. Specific markers, histological findings, and diagnostic clinical features are generally unremarkable in DILD [1,2]. Difficulties arise when signs and symptoms develop after the drug is discontinued rather than during treatment or when no improvement follows discontinuation of the drug. Making a timely and accurate diagnosis of DILD is very important to ensure a favorable outcome [3].

\section{Clinical manifestations and diagnosis of DILD Clinical manifestations}

Laboratory findings and clinical manifestations of DILD, such as cough, fever, dyspnea, and hypoxemia [1-4], are non-specific. DILD is indicated when cough, fever, dyspnea, and/or pleuritic chest pain are observed in 
combination with pertinent radiographic findings, in the absence of evidence of congestive heart failure, infectious disease or malignancy, and when symptoms subside with drug withdrawal. Pulmonary function tests in the majority of DILD cases may reveal a pattern of restrictive abnormality, with decreased values of DLCO. Discontinuation of the drug is essential, and, in more severe cases, administration of corticosteroids may be of therapeutic value.

\section{Histology}

The histological findings of pulmonary drug reactions are often non-specific and mimic those of other conditions, such as idiopathic interstitial pneumonia and collagen vascular disease [5]. Almost, all histopathological subtypes of interstitial lung disease may be observed [3]: diffuse alveolar damage (DAD), chronic interstitial pneumonia [CIP, including non-specific interstitial pneumonia (NSIP), usual interstitial pneumonia (UIP), and desquamative interstitial pneumonia (DIP)], organizing pneumonia (OP), eosinophilic pneumonia (EP), hypersensitivity pneumonitis (HP), and granulomatous lung disease [6-9]. While some drugs, such as minocycline, methotrexate (MTX), and nitrofurantoin, induce stereotypical reactions in the lungs (EP, acute granulomatous interstitial lung disease, and the cellular type of non-specific pneumonia, respectively), other drugs, such as amiodarone and bleomycin, may be associated with more than one histological pattern [3].

\section{High-resolution computed tomography (HRCT) and ${ }^{18}$ F-fluorodeoxyglucose positron emission tomography $\left({ }^{18}\right.$ F-FDG-PET)}

HRCT is currently the best non-invasive method to assess the presence of drug-induced lung disease. The results of HRCT in DILD are similar to those of ILDs from other causes or those of idiopathic interstitial pneumonia. Radiographic manifestations of DILD correspond to those of NSIP, UIP, HP, DAD, cryptogenic OP (COP)/EP, and diffuse pulmonary hemorrhage. HRCT may reveal abnormalities in patients with normal radiographs $[8,10,11]$. Cleverly et al. reported that HRCT had an accuracy of only $45 \%$ for predicting the specific histological reaction pattern of DILD [5]. Thus, HRCT is limited in its ability to predict the histological patterns in drug-induced lung diseases [5]. HRCT can, however, be valuable in identifying findings that suggest an alternative diagnosis and in monitoring responses to treatments.

Akira et al. reported difuuse or multi-focal groundglass opacities with intralobular interstitial thickening as the predominant findings in anti-neoplastic agentinduced pneumonitis. Patchy ground-glass opacities with centrilobular opacities and interlobular septal lines were predominant radiographic findings in antibiotic agentinduced pneumonitis [12].

Recently, the use of ${ }^{18}$ F-FDG-PET in the diagnosis of DILD has been reported. FDG uptake was detected at an extremely early stage when no symptoms or abnormal findings on HRCT were apparent $[13,14]$. PET positivity, however, has no specificity for DILD.

\section{Serum markers}

KL-6 has been reported as a sensitive marker for interstitial lung diseases $[4,15]$. Particular patterns detected by HRCT, such as DAD and CIP, but not COP/EP or $\mathrm{HP}$, are associated with increased KL- 6 levels in the circulation of patients with DILD [6]. Furthermore, surfactant proteins SP-A and SP-D have been reported as specific markers of pulmonary fibrosis [16]. Inomata et al. demonstrated that SP-A, SP-D, and KL-6 levels were increased in the serum of patients with DILD associated with the administration of the epidermal growth factor receptor-tyrosine kinase inhibitor, gefitinib [17].

Serum ADAM8 (a disintegrin and a metalloproteinase 8) concentrations were significantly elevated in patients with drug-induced EP, and after a drug provocation test (DPT), which demonstrated that ADAM8 induction paralleled drug-induced eosinophilic lung inflammation [18].

\section{Bronchoscopy and bronchoalveolar lavage (BAL)}

Bronchoscopy can be helpful in determining the presence of pneumonitis and for the differential diagnosis of lymphangitic carcinomatosis, vasculitis, alveolar hemorrhage, or pneumonia from infectious agents.

Most drug-induced immunological reactions, such as $\mathrm{HP}$ and COP/EP, may be excluded if BAL cytology is normal. The most prominent feature of DILD was a lymphocytic alveolitis, either pure or associated with neutrophil and/or eosinophilic alveolitis along with an imbalance in T lymphocyte phenotype [19]. The most frequent change observed is lymphocytic alveolitis with a preponderance of CD8+ cells. In MTX-induced pneumonitis, CD4+ cells may also be preferentially increased; this increase has also been demonstrated with the use of ampicillin, nitrofurantoin, and sirolimus [20].

\section{Mechanisms involved in DILD}

Many different mechanisms may be involved in the initiation and propagation of DILD [21]. Both cytotoxic and immune mechanisms of action may be involved independently or in combination in the tissue expression of different forms of lung injury [22].

\section{Cytotoxic pulmonary injury}

Multiple mechanisms may be responsible for cytotoxic pulmonary injury due to drugs, including reactive 
oxygen species (ROS) [21,23-25], reduction in deactivation of metabolites of the lung [26-28], impairment of alveolar repair mechanisms [29-31], and release of various cytokines [23]. Many agents may be toxic to the lungs. These include cytotoxic drugs, such as bleomycin, MTX, and cyclophosphamide, and non-cytotoxic drugs, such as nitrofurantoin, sulfasalazine, and amiodarone [32].

Chemotherapy lung is one representative example of cytotoxic lung injury. It is a severe type of pulmonary reaction that develops during or shortly after treatment with chemotherapeutic agents, such as antibiotics, alkylating agents, anti-metabolites, nitrosamines, rapamycin analogs, and podophyllotoxins [4]. Histologically, chemotherapy lung corresponds to DAD [1,3]. Concurrent radiation or oxygen therapy increases the risk of developing chemotherapy lung. Moreover, chemotherapy lung can sometimes develop because of previously unresolved chemotherapy- or radiation-induced damage with additional chemotherapy [3].

\section{Mechanisms of cytotoxic pulmonary injuries}

The pathogenesis of cytotoxic lung injury may include direct injury to pneumocytes or the alveolar capillary endothelium, with subsequent release of cytokines and recruitment of inflammatory cells. The systemic release of cytokines induced by chemotherapeutic agents (e.g., gemcitabine) may also result in capillary leakage and pulmonary edema. Early events in lung injury induced by tricyclic antidepressants may be related to endothelial damage [21] because of impaired tight junctions mediated by amitriptyline-induced perturbations in intracellular calcium [21].

MTX-induced pulmonary toxicity may induce the release of free oxygen radicals, such as nitric oxide, and various cytokines, such as IL- $1 \beta$, TNF- $\alpha$, and TGF- $\beta$. Kim et al. reported that the p38MAPK signaling pathway was associated with a pulmonary inflammatory response [23].

By impairing alveolar repair mechanisms, gefitinib may potentiate the effects of lung injury $[29,30]$. Suzuki et al. have suggested that gefitinib therapy may augment any underlying pulmonary fibrosis through decrease in epidermal growth factor receptor phosphorylation with coincident regenerative epithelial proliferation [31].

The toxic mechanism of amiodarone leads to the disruption of the lysosomal membranes of molecules through protein $\mathrm{C}$ activation and the subsequent release of toxic oxygen radicals, which may induce activation of caspase pathways and lead to apoptosis of lung epithelial cells [24]. An additional mechanism reduces deactivation of toxic metabolites of the drug [26,27].

Pulmonary toxicity may also be caused by the generation of free oxygen radicals by mitomycin $\mathrm{C}$, nitrofurantoin, and bleomycin. These drug-induced ROS generate substances such as $\mathrm{H}_{2} \mathrm{O}_{2}, \dot{\mathrm{O}}_{2^{-}}$, and $\dot{\mathrm{O}} \dot{\mathrm{H}}$ [21]. In vivo and in vitro studies showed bleomycine, a cancer chemotherapeutic agent, to be the cause of pulmonary toxicity, which was mediated, at least partly, by a bleomycin-iron complex, generating toxic $\mathrm{O}_{2}$-derived species within the lung [25]. Particular susceptibility to bleomycin toxicity in the lung may depend on the fact that bleomycin is preferentially distributed in lung tissue and that the lung is relatively deficient in the hydrolase enzyme that detoxifies bleomycin [28].

Nitrofurantoin and bleomycin share the ability to generate $\mathrm{O}_{2}$ radicals and to cause lung damage. The reason that these drugs affect the lungs as their predominant site of toxicity remains unclear. One possibility is the rate of gas exchange and high oxygen load in the lungs, which enables damage due to these drugs [21].

\section{Diagnosis of cytotoxic pulmonary injury}

Drug-induced pulmonary toxicity can be difficult to diagnose because cancer patients are usually administered multiple anti-neoplastic agents; thus, identifying the causative agent becomes difficult. Unfortunately, no single diagnostic test or tissue biopsy is currently available that can definitively confirm a diagnosis of chemotherapy-associated lung disease [33].

Currently, in vitro drug challenge is not a readily available or clinically validated diagnostic assay for cytotoxic lung injury. Reactive drug metabolites are believed to play a role in many drug reactions. Differences in the capacity of cells to detoxify the reactive metabolites of drugs are important determinants in drug toxicity reactions, and these differences could be used as the basis of a diagnostic assay. Microsomes are a source of oxidative enzymes, primarily cytochrome P450 (CYP). Cell viability can be determined after incubating microsomes with PBMCs and the suspected drug in the presence or absence of a microsomal activating system. This assay has not been used for the diagnosis of cytotoxic lung injury. However, this approach may enhance our understanding of selected drugs that cause DILD, paving the way for development of clinically useful assays [34,35].

\section{Immune-mediated pulmonary injuries \\ General pathogenesis of drug allergies}

Exposure to a particular drug can induce immune reactions in a minority of individuals. Although most have not yet been identified, several factors may control this process: the chemical structure of the molecule (antigenic drug determinants); genetic factors including polymorphisms of genes that encode drugs that metabolize enzymes and immune responses; environmental factors (stress, concurrent infection, and pollution); and the nature of drug exposure (dose, duration, frequency, and route of administration) [36]. 


\section{(a) mechanisms of drug allergy}

Our knowledge regarding human immune responses to drugs remains limited. Drug hypersensitivity and other immune reactions are frequently categorized according to Gell and Coombs classification, which includes four categories that reflect distinct immune mechanisms. This variety explains the heterogeneous clinical presentations that can occur [37]. All these reactions are T cell-regulated, but the effector functions are primarily antibody-mediated factor functions (I-III). Most of the reactions in immunemediated DILD may be T cell-mediated. DILD associated with a type III reaction was investigated in a case report. Schatz et al. reported a case of pneumonitis characterized by an eosinophilic interstitial infiltrate with evidence of immunofluorescent staining and immune complex-mediated activation of the classic complement pathway [38].

\section{(b) drug recognition}

With regard to the role of T cells in drug hypersensitivity, a question arises: how do T cells recognize drugs? [34].

\section{(b)-(i) hapten concept}

The recognition of small molecules like drugs by $\mathrm{B}$ and $\mathrm{T}$ cells is usually explained by the hapten concept. In their native states, most drugs are not immunogenic. Many drugs have low molecular weights $(<1000 \mathrm{kDa})$ and must be covalently bound to high-molecular-weight carrier proteins to become effective immunogens $[36,39]$. A hapten may directly bind to an immunogenic peptide presented by a major histocompatibility complex molecule.

A drug that is not chemically reactive per se may become reactive on metabolism [39]. Once formed, these reactive metabolites may cause cytotoxicity and/or become covalently bound to cellular proteins [40]. The ability to form immunogenic complexes and mount an immune response to these complexes differs among individuals [39].

\section{(b)-(ii) p-i concept}

Pichler et al. elaborated another possibility; namely, a pharmacological interaction between drugs and immune receptors (p-i concept) [36]. They found that chemically inert drugs, which could not covalently bind to peptides or proteins, could directly activate certain $\mathrm{T}$ cells if they happened to bear $\mathrm{T}$ cell receptors that could interact with the drug. According to the "p-i" model, which is metabolism- and processing-independent, the structural features of a drug elicit an immunological response [36].

\section{(b)-(iii) danger model}

One of the major functions of the adaptive immune system is to distinguish "self" from "non-self." If the immune system encounters self proteins, it will result in tolerance. In contrast, encounter with non-self or foreign proteins leads to an immune response.

Matzinger proposed an alternative explanation, labeled the Danger Model, of the generation of immune responses [40]. According to Matzinger, the activation of dendritic cells can be induced by endogenous danger signals, such as - release by tissues undergoing stress, damage, or abnormal death, and by exogenous danger signals elaborated by pathogens. Certain drugs may cause cell injury and act as immunologic triggers.

A schematic representation of drug-induced pulmonary effects and toxicity is provided in Figure 1.

\section{Diagnostic tests in drug hypersensitivity reactions}

In vitro diagnostic tests are useful in cases of clinical uncertainty to confirm a clinical diagnosis. To determine which test is optimal for confirming the clinical diagnosis of an adverse drug reaction, an appreciation of the pathophysiological mechanism(s) responsible for the adverse reaction is critical [34]. Potentially useful diagnostic tests in DILD include the drug lymphocyte stimulation test (DLST), LMT [41], and flow cytometry.

\section{Mechanisms and diagnosis of immune-mediated DILD}

Lungs provide a barrier to illness in which the immune system is chronically activated to provide optimal host defense. This constant, low-level activation provides a milieu that may facilitates pro-inflammatory signals and subsequent immune system responses.

Minocycline-induced pneumonia (MIP) is generally manifested as EP. A central role for $\mathrm{T}$ lymphocytes in the immunologic reaction to MIP was suggested by Gillon et al., who identified lymphocyte-mediated specific cytotoxicity against minocycline-bearing alveolar macrophages in vitro [42]. Their findings, however, do not explain the presence of pulmonary eosinophilia, which is a characteristic feature of MIP. Thus, further investigations are needed to elucidate the pathophysiology of MIP. Three different mechanisms of amiodarone induced lung disease have been suggested: a direct toxic effect, an immune-mediated mechanism, the angiotensin enzyme system activation [9]. From the immunological perspective, Kuruma et al. reported that the Th1/Th2 balance may influence amiodarone metabolism and may be a powerful indicator of amiodarone-induced subclinical lung toxicity [43].

\section{(a) diagnosis of immune-mediated DILD}

Causative drugs are determined from the history of drug exposure and any response to withdrawal of an implicated drug. An in vitro test such as the DLST can only detect the presence of sensitization, but cannot predict whether the sensitization will lead to symptoms [44]. 


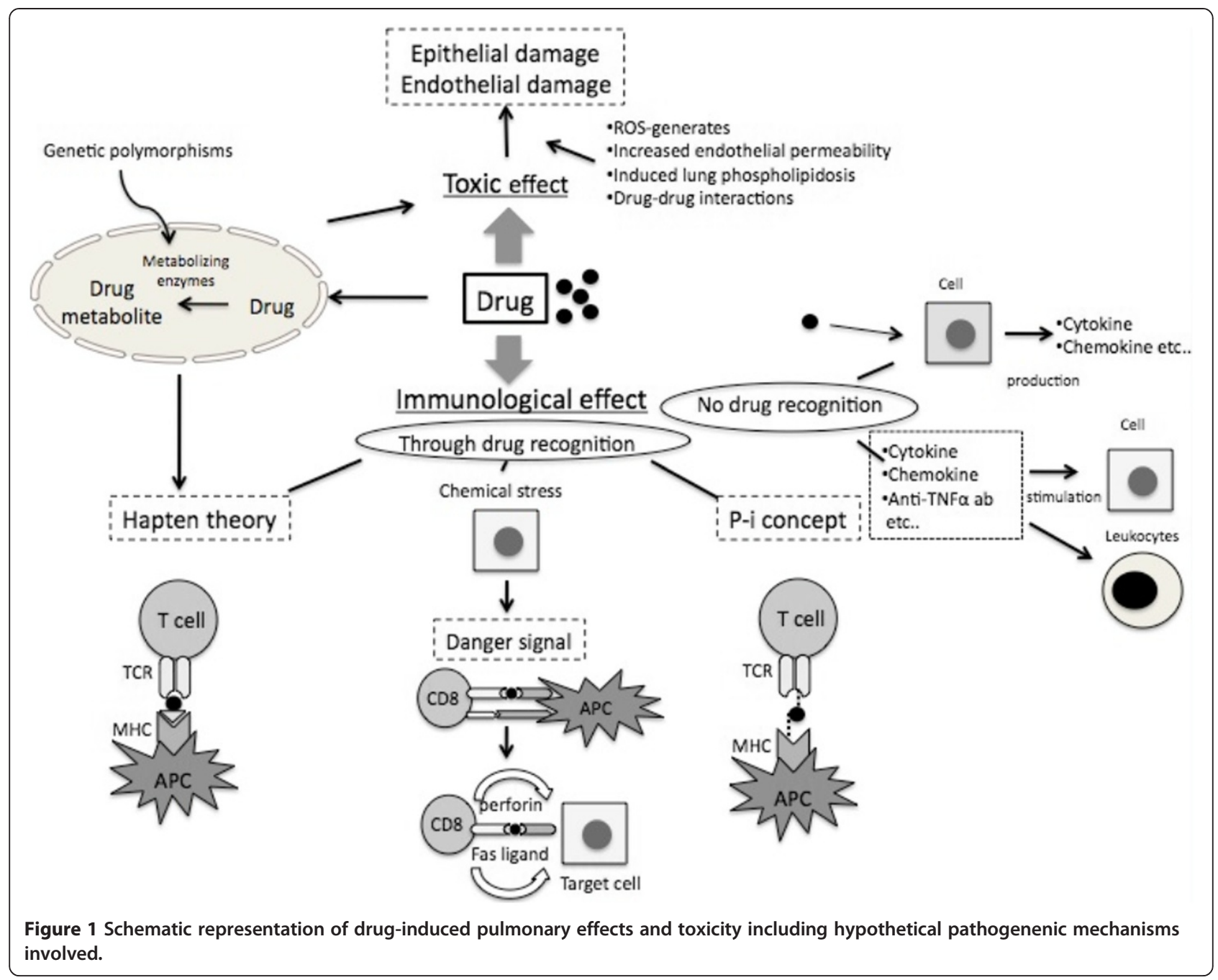

Provocation tests can detect not only the presence of sensitization to a drug, but also the clinical manifestations induced by this sensitization [44]. The utility of skin testing in DILD, however, has not been reported.

\section{(a)-(i) in vitro tests for DILD}

DLST and LMT are bioassays that help to confirm the presence of drug-sensitized lymphocytes. The DLST verifies the growth of sensitized lymphocytes after a drug is used for antigen stimulation, while the LMT identifies the cytokines or chemokines produced by sensitized lymphocytes after a drug is used for antigen stimulation [45].

The DLST is the most commonly used in vitro test for detecting the causative drug in cases of drug allergy. The causes of drug allergies determined using the DLST have been extensively reported in cases of drug eruption $[44,46,47]$. Laboratory-based in vitro methods, such as the DLST, have numerous advantages, including absolute safety, ability to assess $\mathrm{T}$ cell responses to multiple drugs simultaneously, and absence of risk of developing additional drug allergies [44]. This technique measures the uptake of a DNA precursor (tritiated $\left[{ }^{3} \mathrm{H}\right]$ thymidine) after lymphocytes have been exposed to an antigen in vitro. This test is associated with blast formation by lymphocytes [44].

The LMT demonstrates the presence of sensitized lymphocytes when granulocytes, either alone or mixed with normal lymphocytes, exhibit migration inhibition when cultured at optimal drug concentrations. Saito et al. reported that the LMT had a higher positive response rate than the DLST for several hypersensitivity symptoms, such as skin eruptions and hepatic injury [45].

While DLST has been widely used in the diagnosis of DILD in Japan, this is not the case in other countries. Compelling data as to the sensitivity and specificity of the DLST for DILD is currently lacking. A cell-mediated hypersensitivity reaction on DLST is the basis for diagnosis of gold-induced pneumonia (GIP). Tomioka and 
King included CD8+ lymphocytic alveolitis and a positive DLST in their diagnostic scheme for GIP [39]. However, GIP is rarely a clinical problem at the present time. Studies on the use of DLST in DIP are far from well controlled. Based on data that compared the results of the DLST and provocation tests for patients with DILD, DLST contributed little in detecting the causative agents in these patients $[48,49]$.

DLST is believed to be insensitive to MIP. Toyoshima et al. reported the results of DLST for minocycline in six patients; in all cases, the results were negative [50]. In addition, suppressive effects of minocycline on $\mathrm{T}$ cell proliferation have been described [51,52].

For MTX and Kampo (Japanese herbal) drugs, the results of DLST tend to be overestimated. Many reports have provided evidence that the uptake of ${ }^{3} \mathrm{H}$ thymidine into lymphocytes in the presence of MTX may be explained by the upregulated incorporation of thymidine from the extracellular space following the depletion of the intracellular thymidine pool caused by MTX. In one study, MTX created an early block in the cell cycle without reducing the cellular uptake of ${ }^{3} \mathrm{H}$-thymidine [53]. Hoffman also found a discrepancy between the formation of blast-like cells and high thymidine uptake in MTX-treated, mitogen-stimulated lymphocytes [54]. Hirata et al. showed that DLST using MTX was inadequate in confirming MTX-induced DILD [55].

Kampo drugs are generally contaminated with nonspecific mitogens from plants. Mantani et al. reported positive DLST results for Kampo drugs in $85.7 \%$ of enrolled patients not taking any Kampo medicines [56]. In addition, several studies reported discrepancies between DLST findings and results of provocation drug tests in Kampo drugs $[7,18,48,49]$.

Leukocyte migration inhibition factor production has also been observed in well-established cases of hypersensitivity pneumonitis, such as that due to beryllium $[42,57]$. Various reports have drawn attention to the positive results of this test in cases of DILD due to different drugs, such as minocycline, amiodarone, propranolol, nitrofurantoin, gold salts, MTX, and paclitaxel [41,57-61]. However, the number of samples used in these reports were small.

CD69 upregulation on $\mathrm{T}$ cells has been reported as an in vitro marker for delayed-type drug hypersensitivity reactions [62]. Compared with other early $\mathrm{T}$ cell activation markers, such as CD71 or CD25, CD69 appeared to be most suitable, as it was rapidly upregulated and showed the greatest difference from baseline values [63].

CD69 upregulation was shown to be drug-specific and not an inherent property of cells derived from patients. It did not occur in unstimulated cultures or in drugstimulated PBMCs from non-allergic donors. Cells from drug-allergic subjects reacted only to the causative drug, but not to any other tested drugs [63]. This assay has not been used for the diagnosis of DILD. However, this approach may enhance our understanding of selected drugs that cause DILD.

\section{(a)-(ii) drug provocation tests (DPT)}

Rechallenge of patients with DILD is generally considered unethical as the pulmonary damage caused by DILD is largely irreversible, and re-challenge increases the risk to the patient. Re-test of drugs has been safely performed in some patients, although a fatality was reported following a re-test with MTX in one case [64]. Several investigators have conducted re-tests with minocycline to establish an accurate diagnosis [65] with no reported morbidity. Similar findings have been reported for EP induced by other drugs, such as sulfalazine [3], amoxicillin [7], and nimesulide [66].

Recently, Yasui et al [48]. proposed a DPT method for mild DILD. DPT was performed in 58cases, 41 of which showed positive results. This test was initiated by administering the lowest dosage of the suspected causal drug that could achieve a response, and then gradually increasing the dose at daily intervals until a normal daily dose was reached or symptoms occurred. This DPT protocol was deemed useful according to the criteria provided by Yasui et al $[48,49]$. Their diagnostic criteria for DIP included a $1^{\circ} \mathrm{C}$ increase in body temperature and one or more of the following an increase in the alveolararterial difference in oxygen tension (A-aDO2) of $>10 \mathrm{mmHg}$; an increase $>20 \%$ in white blood cell count; and positive conversion of $\mathrm{C}$-reactive protein $[48,49]$.

\section{Pulmonary inflammation and fibrosis}

Monoclonal antibodies have emerged as a new class of agents that can cause DILD. The number of cases of ILD triggered by anti-TNF- $\alpha$ agents is increasing. TNF- $\alpha$ has both pro- and anti-fibrotic effects. TNF- $\alpha$ can promote pulmonary tissue repair, eliminating inflammatory cells by inducing their apoptosis [52,67,68]. Increase in the local releases of inflammatory cell-derived proteolytic enzymes may enhance the potential pulmonary toxicity of MTX, which may then be potentiated by an anti- TNF- $\alpha$ agent, resulting in impaired apoptosis of infiltrating inflammatory cells [67]. Anti- TNF- $\alpha$ therapy may also result in systemic and/or pulmonary shifts towards anti-inflammatory cytokines, such as TGF- $\beta 1$, thus contributing to a profibrotic state [67], which would explain the exacerbation seen in pulmonary fibrosis.

Rituximab, an anti-CD20 antibody, has been reported to induce a heterogeneous spectrum of lung disease. The release of cytokines, such as TNF- $\alpha$, IFN- $\alpha$, IL- 6 , and IL-8, has been postulated as the mechanism responsible. Other possible mechanisms of induction include complement activation or indirect cytotoxic $\mathrm{T}$ lymphocyte 
(CTL) activation [69]. CTL activation appears to be induced by dendritic cells that, in turn, are stimulated by cell-derived peptides resulting from rituximabinduced cell destruction. These activated CTL's may cause vascular and alveolar damage thereby, initiating lung injury $[14,69]$.

\section{Drug interactions and cross-reactivity}

Drug interactions that cause ILD have not been reported except in one case report by McFadden et al., who reported a case of "gold-naproxen pneumonitis." They hypothesized that naproxen interfered with the ability to restrain the immune response to gold, which resulted in clinical pneumonitis that resolved only when both naproxen and gold were discontinued. This was the first suggestion of a "drug interaction" that could cause lung injury [70].

Cross-reactivity has not been documented with drugs that cause ILD [3].

\section{Host susceptibility in DILD}

The mechanisms by which some patients exhibit high susceptibility while others appears to be resistant remain largely unknown. However, several possibilities have been suggested.

The human leukocyte antigen (HLA) complex plays a central role in presenting antigens for $\mathrm{T}$ cell recognition. In certain immune based disorders, the pattern of HLA class II allele presentation confers both resistance and susceptibility to disease onset. Rheumatoid arthritis (RA) patients who tested positive for HLA-B40 had a 10.5fold relative risk and those positive for Dw1 had a 6.2fold relative risk of developing gold-induced pneumonitis as compared with RA patients without these antigens [71].

Both genetic and intrinsic factors can affect the disposition of certain drugs (absorption, distribution, metabolism, and excretion). Several different xenobioticmetabolizing CYP and conjugation enzymes have been shown to be present in the lung [72-74].

CYP single nucleotide polymorphisms are among the key factors known to cause variations in drug responses among individuals [75]. Wijnen et al. indicated that DILD might be attributed to a reduced metabolic capacity because of CYP enzymes. They indicated that various CYP genotypes presented a substantial susceptibility risk factor for the development of DILD [76]. Therefore, genotyping prior to drug prescription may be clinically useful for predicting and preventing DILD.

\section{Conclusion}

This review has focused on the mechanistic aspects of DILD, describing several different mechanisms that may be involved in the initiation and propagation of DILD.
With better clarification of these processes, the prediction of DILD should be possible in the not too distant future. In addition, the validation of previously developed techniques and the development of new tests will contribute enormously to progress in the diagnostic evaluation of DILD.

\section{Competing interests}

The author declares that he has no competing interest.

Received: 13 December 2011 Accepted: 16 May 2012

Published: 31 May 2012

\section{References}

1. Cooper JA Jr, White DA, Matthay RA: Drug-induced pulmonary disease. Part 1: Cytotoxic drugs. Am Rev Respir Dis 1986, 133:321-340.

2. Cooper JA Jr, White DA, Matthay RA: Drug-induced pulmonary disease. Part 2: Noncytotoxic drugs. Am Rev Respir Dis 1986, 133:488-505.

3. Camus P, Fanton A, Bonniaud P, Camus C, Foucher P: Interstitial lung disease induced by drugs and radiation. Respiration 2004, 71:301-326.

4. Vahid B, Marik PE: Pulmonary complications of novel antineoplastic agents for solid tumors. Chest 2008, 133:528-538.

5. Cleverley JR, Screaton NJ, Hiorns MP, Flint JD, Müller NL: Drug-induced lung disease: high-resolution CT and histological findings. Clin Radiol 2002, 57:292-299.

6. Ohnishi H, Yokoyama A, Yasuhara Y, Watanabe A, Naka T, Hamada H, Abe M, Nishimura K, Higaki J, Ikezoe J, Kohno N: Circulating KL-6 levels in patients with drug induced pneumonitis. Thorax 2003, 58:872-875.

7. Matsuno O, Takenaka R, Ando M, Miyazaki E, Kumamoto T: AmoxicillinInduced Eosinophilic Pneumonia with Granulomatous Reaction: Discrepancy between Drug-Induced Lymphocyte Stimulation Test Findings and the Provocation Drug Test. Allergy Asthma Clin Immun 2007, 3:70-72.

8. Silva $\mathrm{Cl}$, Müller NL: Drug-induced lung diseases: most common reaction patterns and corresponding high-resolution CT manifestations. Semin Ultrasound CT MR 2006, 27:111-116.

9. Papiris SA, Triantafillidou C, Kolilekas L, Markoulaki D, Manali ED: Amiodarone: review of pulmonary effects and toxicity. Drug Saf 2010, 33:539-558

10. Myers JL, Limper AH, Swensen SJ: Drug-induced lung disease: a pragmatic classification incorporating HRCT appearances. Semin Respir Crit Care Med 2003, 24:445-454.

11. Ellis SJ, Cleverley JR, Müller NL: Drug-induced lung disease: high-resolution CT findings. Am J Roentgenol 2000, 175:1019-1024.

12. Akira $M$, Ishikawa $H$, Yamamoto S: Drug-induced pneumonitis: thin-section CT findings in 60 patients. Radiology 2002, 224:852-860.

13. Yamane T, Daimaru O, Ito S, Nagata T, Yoshiya K, Fukaya N, Ito S, Imai T, Uchida H: Drug-induced pneumonit is detected earlier by 18 F-FDG-PET than by high-resolution $\mathrm{CT}$ : a case report with non-Hodgkin's lymphoma. Ann Nucl Med 2008, 22:719-722.

14. Nieuwenhuizen L, Verzijlbergen FJ, Wiltink E, Grutters JC, Biesma DH: A possible role of $18 \mathrm{~F}$-FDG positron-emission tomography scanning in the early detection of rituximab-induced pneumonitis in patients with nonHodgkin's lymphoma. Haematologica 2008, 93:1267-1269.

15. Kobayashi J, Kitamura S: KL-6: a serum marker for interstitial pneumonia. Chest 1995, 108:311-315

16. Takahashi H, Fujishima T, Koba H, Murakami S, Kurokawa K, Shibuya Y, Shiratori M, Kuroki Y, Abe S: Serum surfactant proteins A and D as prognostic factors in idiopathic pulmonary fibrosis and their relationship to disease extent. Am J Respir Crit Care Med 2000, 162:1109-1114.

17. Inomata S, Takahashi H, Nagata M, Yamada G, Shiratori M, Tanaka H, Satoh M, Saitoh T, Sato T, Abe S: Acute lung injury as an adverse event of gefitinib. Anticancer Drugs 2004, 15:461-467.

18. Matsuno O, Ono E, Ueno T, Takenaka R, Nishitake T, Hiroshige S, Miyazaki E, Kumamoto T, Higuchi Y: Increased serum ADAM8 concentration in patients with drug-induced eosinophilic pneumonia -ADAM8 expression depends on the allergen route of entry. Respir Med 2010, 104:34-39.

19. Akoun GM, Cadranel JL, Rosenow EC 3rd, Milleron BJ: Bronchoalveolar lavage cell data in drug-induced pneumonit is. Allerg Immunol Paris 1991, 23:245-252 
20. Costabel U, Guzman J, Bonella F, Oshimo S: Bronchoalveolar lavage in other interstitial lung diseases. Semin Respir Crit Care Med 2007, 28:514-524

21. Ryrfeldt A: Drug-induced inflammatory responses to the lung. Toxicol Lett 2000, 112-113:171-176.

22. Pietra GG: Pathologic mechanisms of drug-induced lung disorders. J Thorac Imag 1991, 6:1-7

23. Kim YJ, Song M, Ryu JC: Mechanisms underlying methotrexate-induced pulmonary toxicity. Expet Opin Drug Saf 2009, 8:451-458.

24. Baritussio A, Marzini S, Agostini M, Alberti A, Cimenti C, Bruttomesso D, Manzato E, Quaglino D, Pettenazzo A: Amiodarone inhibits lung degradation of SP-A and perturbs the distribution of lysosomal enzymes. Am J Physiol Lung Cell Mol Physiol 2001, 281:L1189-L1199.

25. Gram TE: Chemically reactive intermediates and pulmonary xenobiotic toxicity. Pharmacol Rev 1997, 49:297-341.

26. Reasor MJ, Kacew S: An evaluation of possible mechanisms underlying amiodarone-induced pulmonary toxicity. Proc Soc Exp Biol Med 1996, 212:297-304.

27. Massey TE, Leeder RG, Rafeiro E, Brien JF: Mechanisms in the pathogenesis of amiodarone-induced pulmonary toxicity. Can J Physiol Pharmacol 1995, 73:1675-1685

28. Cooper JA Jr, Zitnik RJ, Matthay RA: Mechanisms of drug-induced pulmonary disease. Annu Rev Med 1988, 39:395-404

29. Takano T, Ohe Y, Kusumoto M, Tateishi U, Yamamoto S, Nokihara H, Yamamoto N, Sekine I, Kunitoh H, Tamura T, Kodama T, Saijo N: Risk factors for interstitial lung disease and predictive factors for tumor response in patients with advanced non-small cell lung cancer treated with gefitinib. Lung Cancer 2004, 45:93-104

30. Miettinen PJ, Warburton D, Bu D, Zhao JS, Berger JE, Minoo P, Koivisto T, Allen L, Dobbs L, Werb Z, Derynck R: Impaired lung branching morphogenesis in the absence of functional EGF receptor. Dev Biol 1997, 186:224-236.

31. Suzuki H, Aoshiba K, Yokohori N, Nagai A: Epidermal Growth Factor Receptor Tyrosine Kinase Inhibition Augments a Murine Model of Pulmonary Fibrosis. Cancer Res 2003, 63:5054-5059.

32. Rossi SE, Erasmus JJ, MCAdams HP, Sporn TA, Goodman PC: Pulmonary drug toxicity: radiologic and pathologic manifestations. Radiographics 2000, 20:1245-1259.

33. Limper AH: Chemotherapy-induced lung disease. Clin Chest Med 2004, 25:53-64.

34. Rieder MJ: In vivo and in vitro testing for adverse drug reactions. Pediatr Clin North Am 1997, 44:93-111.

35. Shear NH, Spielberg SP, Grant DM, Tang BK, Kalow W: Differences in metabolism of sulfonamides predisposing to idiosyncratic toxicity. Ann Intern Med 1986, 105:179-184.

36. Schnyder B, Pichler WJ: Mechanisms of drug-induced allergy. Mayo Clin Proc 2009, 84:268-272.

37. Coombs PRA, Gell PGH: Classification of allergic reactions responsible for clinical hypersensitivity and disease. In Clinical aspects of immunology. Edited by Gell PRA. Oxford: Oxford University Press; 1968:575-596.

38. Schatz PL, Mesologites D, Hyun J, Smith GL, Lahiri B: Captopril-induced hypersensitivity lung disease. An immune-complex-mediated phenomenon. Chest 1989, 95:685-687.

39. Gruchalla RS: Drug metabolism, danger signals, and drug-induced hypersensitivity. J Allergy Clin Immunol 2001, 108:475-488.

40. Matzinger P: The danger model: a renewed sense of self. Science 2002, 296:301-305.

41. Tomioka R, King TE Jr: Gold-induced pulmonary disease: clinical features, outcome, and differentiation from rheumatoid lung disease. Am J Respir Crit Care Med 1997, 155:1011-1020.

42. Guillon JM, Joly P, Autran B, Denis M, Akoun G, Debré $P$, Mayaud C: Minocycline-induced cell-mediated hypersensitivity pneumonitis. Ann Intern Med 1992, 117:476-481.

43. Kuruma T, Maruyama T, Hiramatsu S, Yasuda Y, Yasuda S, Odashiro K Harada M: Relationship between amiodarone-induced subclinical lung toxicity and Th1/Th2 balance. Int J Cardiol 2009, 134:224-230.

44. Pichler WJ, Tilch J: The lymphocyte transformation test in the diagnosis of drug hypersensitivity. Allergy 2004, 59:809-820.

45. Saito M, Yagi M, Uno K, Takanaka K: Comparative study of the usefulness of the drug-induced lymphocyte stimulation test and the leukocyte migration test in drug allergies. Biol Pharm Bull 2008, 31:299-304.
46. Mori H, Yamanaka K, Kaketa M, Tamada K, Hakamada A, Isoda K, Yamanishi K, Mizutani H: Drug eruption caused by azathioprine: value of using the druginduced lymphocytes stimulation test for diagnosis. J Dermatol 2004, 31:731-736.

47. Kardaun SH, de Monchy JG: Acute generalized exanthematous pustulosis caused by morphine, confirmed by positive patch test and lymphocyte transformation test. J Am Acad Dermatol 2006, 55:S21-S23.

48. Yasui M, Fujimura M: The significance of DLST and drug provocation test. Jpn J Chest Dis 2003, 62:885-891. in Japanese with English abstract.

49. Matsuno O, Okubo T, Hiroshige S, Takenaka R, Ono E, Ueno T, Nureki S, Ando M, Miyazaki E, Kumamoto T: Drug-induced lymphocyte stimulation test is not useful for the diagnosis of drug-induced pneumonia. Tohoku J Exp Med 2007, 212:49-53.

50. Toyoshima M, Sato A, Hayakawa H, Taniguchi M, Imokawa S, Chida K: A clinical study of minocycline-induced pneumonitis. Intern Med 1996, 35:176-179.

51. Ingham E, Turnbull L, Kearney JN: The effects of minocycline and tetracycline on the mitotic response of human peripheral bloodlymphocytes. J Antimicrob Chemother 1991, 27:607-617.

52. Thong $\mathrm{YH}$, Ferrante $\mathrm{A}$ : Inhibition of mitogen-induced human lymphocyte proliferative responses by tetracycline analogues. Clin Exp Immunol 1979, 35:443-446.

53. Afane M, Ramos F, Chassagne J, Dubost JJ, Galtier B, Sauvezie B: Discrepancy between $3 \mathrm{H}$-thymidine uptake and cell cycle studies in stimulated lymphocyte cultures treated with methotrexate. Clin Exp Rheumatol 1989, 7:603-608.

54. Hoffmann CC, Ho YK, Blakley RL, Thompson JS: Comparative effects of selected antifolates on transforming human lymphocyt es and on established human lymphoblastic cell lines. Biochem Pharmacol 1976, 25:1947-1954

55. Hirata S, Hattori N, Kumagai K, Haruta Y, Yokoyama A, Kohno N: Lymphocyte transformation test is not helpful for the diagnosis of methotrexate-induced pneumonit is in patients with rheumatoid arthritis. Clin Chim Acta 2009, 407:25-29.

56. Mantani N, Kogure T, Tamura J, Shimada Y, Terasawa K: Lymphocyte transformation test for medicinal herbs yields false-positive results for first-visit patients. Clin Diagn Lab Immunol 2003, 10:479-480.

57. Price $C D$, Williams WJ, Pugh A, Joynson DH: Role of in vitro and in vivo tests of hypersensitivity in beryllium workers. J Clin Pathol 1977, 30:24-28.

58. Akoun GM, Gauthier-Rahman S, Milleron BJ, Perrot JY, Mayaud CM: Amiodarone-induced hypersensitivity pneumonitis: Evidence of an immunological cell-mediated mechanism. Chest 1984, 85:133-135.

59. Akoun GM, Gauthier-Rahman S, Mayaud CM, Touboul JL, Denis MF: Leukocyte migration inhibition in methotrexate-induced pneumonitis Evidence for an immunologic cell-mediated mechanism. Chest 1987 91:96-99.

60. Gauthier-Rahman S, Akoun GM, Milleron BJ, Mayaud CM: Leukocyte migration inhibition in propranolol-induced pneumonitis. Evidence for an immunologic cell-mediated mechanism. Chest 1990, 97:238-241.

61. Fujimori K, Yokoyama A, Kurita Y, Uno K, Saijo N: Paclitaxel-induced cellmediated hypersensitivity pneumonitis. Diagnosis using leukocyte migration test, bronchoalveolar lavage and transbronchial lung biopsy. Oncology 1998, 55:340-344

62. Beeler A, Zaccaria L, Kawabata T, Gerber BO, Pichler WJ: CD69 upregulation on T cells as an in vitro marker for delayed-type drug. Allergy 2008, 63:181-188

63. Maino VC, Suni MA, Ruitenberg JJ: Rapid flow cytometric method for measuring lymphocyte subset activation. Cytometry 1995, 20:127-133.

64. Imokawa S, Colby TV, Leslie KO, Helmers RA: Methotrexate pneumonit is: review of the literature and histopathological findings in nine patients. Eur Respir J 2000, 15:373-381.

65. Sitbon O, Bidel N, Dussopt C, Azarian R, Braud ML, Lebargy F, Fourme T, de Blay F, Piard F, Camus P: Minocycline pneumonitis and eosinophilia. A report on eight patients. Arch Intern Med 1994, 154:1633-1640.

66. Perng DW, Su HT, Tseng CW, Lee YC: Pulmonary infiltrates with eosinophilia induced by nimesulide in an asthmatic patient. Respiration 2005, 72:651-653.

67. Ramos-Casals M, Perez-Alvarez R, Perez-de-Lis M, Xaubet A, Bosch X, BIOGEAS Study Group: Pulmonary disorders induced by monoclonal antibodies in patients with rheumatologic autoimmune diseases. Am J Med 2011, 124:386-394. 
68. Villeneuve E, St-Pierre A, Haraoui B: Interstitial pneumonit is associated with infliximab therapy. J Rheumatol 2006, 33:1189-1193.

69. Lioté H, Lioté F, Séroussi B, Mayaud C, Cadranel J: Rituximab-induced lung disease: A systematic literature review. Eur Respir J 2010, 35:681-687.

70. McFadden RG, Fraher LJ, Thompson JM: Gold-naproxen pneumonitis. A toxic drug interaction? Chest 1989, 96:216-218

71. Hakala M, van Assendelft AH, llonen J, Jalava S, Tiilikainen A: Association of different HLA antigens with various toxic effects of gold salts in rheumatoid arthritis. Ann Rheum Dis 1986, 45:177-182.

72. Higenbottam T, Kuwano K, Nemery B, Fujita Y: Understanding the mechanisms of drug-associated interstitial lung disease. Br J Cancer 2004, 91(Suppl 2):S31-S37.

73. Hukkanen J, Pelkonen O, Raunio H: Expression of xenobiotic-metabolizing enzymes in human pulmonary tissue: possible role in susceptibility for ILD. Eur Respir J Supp/ 2001, 32:122s-126s.

74. Castell JV, Donato MT, Gómez-Lechón MJ: Metabolism and bioactivation of toxicants in the lung. The in vitro cellular approach. Exp Toxicol Pathol 2005, 57(Suppl 1):189-204.

75. Wilkinson GR: Drug metabolism and variability among patients in drug response. N Engl J Med 2005, 352:2211-2221.

76. Wijnen PA, Drent M, Nelemans PJ, Kuijpers PM, Koek GH, Neef C, Haenen GR, Bekers O: Role of cytochrome P450 polymorphisms in the development of pulmonary drug toxicity: a case-control study in the Netherlands. Drug Saf 2008, 31:1125-1134.

doi:10.1186/1465-9921-13-39

Cite this article as: Matsuno: Drug-induced interstitial lung disease: mechanisms and best diagnostic approaches. Respiratory Research 2012 13:39.

\section{Submit your next manuscript to BioMed Central and take full advantage of:}

- Convenient online submission

- Thorough peer review

- No space constraints or color figure charges

- Immediate publication on acceptance

- Inclusion in PubMed, CAS, Scopus and Google Scholar

- Research which is freely available for redistribution 